\title{
O animal estético e político em "Carta a uma senhorita em Paris", de Julio Cortázar
}

\section{The aesthetic and political animal in "Letter to a lady in Paris", by Julio Cortázar}

\section{El animal estético y político en "Carta a una señorita en París", de Julio Cortázar}

\author{
iD Hiandro Bastos da Silva \\ Universidade Federal do Oeste do Pará (UFOPA), Fátima, Santarém, Pará, Brasil. \\ E-mail: hiandrobastos@hotmail.com \\ (iD) Lauro Roberto do Carmo Figueira \\ Universidade Federal do Oeste do Pará (UFOPA), Fátima, Santarém, Pará, Brasil. \\ E-mail: laurocf@yahoo.com.br
}

\begin{abstract}
Resumo: Este estudo investiga a presença do animal no conto Carta a uma senhorita em Paris (1951), de Julio Cortázar. Por meio de uma perspectiva biopolítica, proposta por Giorgio Agamben, estabeleceu-se um paralelo entre a dominação do não humano na cultura ocidental e a dominação do humano no registro contemporâneo - debate instalado nesta narrativa. Destarte, apuram-se potências virtuais no animal cortaziano, com fundamentação em Gabriel Giorgi, entre outros autores, que assediam as estruturas opressivas da realidade factual, reconfigurando as concepções de humanidade e animalidade para se alcançar novas economias de vida.
\end{abstract}

Palavras-chave: Animal. Homem. Biopolítica. Julio Cortázar.

Abstract: This study investigates the presence of the animal in the short story Letter to a lady in Paris (1951), by Julio Cortázar. Through a biopolitical perspective, proposed by Giorgio Agamben, a parallel was 
established between the domination of the non-human in Western culture and the domination of the human in the contemporary register - a debate installed in the aforementioned narrative. Thus, virtual potencies are found in the Cortezian animal, based on Gabriel Giorgi, among other authors, who harass the oppressive structures of factual reality, reconfiguring the conceptions of humanity and animality in order to reach new economies of life.

Key-words: Animal. Men. Biopolitics. Julio Cortázar.

Resumen: Este estudio investiga la presencia del animal en el cuento Carta a una señorita en París (1951), de Julio Cortázar. Mediante una perspectiva biopolítica, propuesta por Giorgio Agamben, se estableció un paralelo entre la dominación de lo no humano en la cultura occidental y la dominación de lo humano en el registro contemporáneo - debate instalado en esta narrativa. Así, se encontraron potencias virtuales en el animal cortaziano, basado en Gabriel Giorgi, entre otros autores, que asedian las estructuras opresivas de la realidad fáctica, reconfigurando las concepciones de humanidad y animalidad para lograr nuevas economías de vida.

Palabras-clave: Animal. Hombre. Biopolítica. Julio Cortázar.

Submetido em 04 de junho de 2021.

Aceito em 02 de agosto de 2021.

Publicado em 03 de fevereiro de 2022. 


\section{Introdução}

A presença dos animais na obra Bestiário (1951), de Julio Cortázar (1914-1984), notabiliza-se pela abordagem revisionista do status quo do humano e da humanidade. Recolocados no cotidiano, sob uma modulação crítica, esses animais indagam a respeito das disjunções entre homem e animal, que coordenam as relações, bem como as subjetividades e os saberes. Neste sentido, a cisão homem/animal, responsável por inaugurar hierarquias entre os corpos, orienta o imaginário estatal a promover suas políticas de vida e de morte. Opondo-se a tal lógica, o conto em estudo Carta a uma senhorita em Paris (1951), do autor supracitado, desmantela as hierarquias ao aproximar homem e animal, problematizando os meios pelos quais a cultura produz o humano em oposição ao não humano, redefinindo as fronteiras entre ambos.

A questão animal, na ficção literária, revela-se fundamental para se compreender e questionar as técnicas de poder que exercem controle político sobre as vidas e determinam o destino dos corpos, de acordo com as reflexões de Michel Foucault (1975, 1976, 1979) e Giorgio Agamben (1995, 1996). Considerando isso, Gabriel Giorgi (2016) aproxima as discussões acerca do animal na Literatura e da biopolítica para interrogar a legitimidade das formas de vida reconhecíveis, fazendo dos estudos do animal na Literatura um espaço de debate "[...] onde se mobilizam as molduras de significação que fazem inteligível a vida como ‘humana' [...].” (2016, p. 12). Deste modo, observa-se o animal escrito transformar-se em um signo vivo de contestação ao controle político responsável por distribuir os corpos e dar-Ihes visibilidade. Nesta perspectiva, o animal emerge nas produções literárias como uma forma instável, contrária aos critérios ordenadores, reinserindo-se na cultura como elemento primordial para a construção de novas políticas do viver e novas éticas do morrer.

Os coelhos regurgitados em Carta a uma senhorita em Paris se manifestam, então, como este signo de contestação ao biopo- 
O animal estético e político em "Carta a uma senhorita em Paris", de Julio Cortázar Hiandro Bastos da Silva • Lauro Roberto do Carmo Figueira

der, em virtude de uma indiferença à distribuição normativa dos corpos, representada na narrativa. Nesta direção, o mecanismo que Agamben chama de "máquina antropológica do humanismo" (2007, p. 51) possui relevância, pois conecta a articulação homem e animal ao paradigma vidas por preservar e vidas por desamparar - justamente a relação que os coelhos da trama cortaziana promovem. Logo, o conto narra uma circunstância em que a figura do animal se faz íntima do protagonista (que oscila entre a condição de vida por proteger e vida por desamparar), projetando-se sobre a sua psique.

Neste estudo, portanto, intenta-se tecer considerações relativas ao modo pelo qual o animal movimenta linguagens, imagens e sentidos no interior do conto Carta a uma senhorita em Paris. Esse animal funciona como engrenagem principal da máquina narrativa de Cortázar, operando a desconstrução do real ordinário - organizado por dicotomias e normativas que atravessam as gramáticas corporais. Consequentemente, constatam-se formas de vida que se iluminam e se potencializam reciprocamente à margem do ordenamento político, como resultado do retorno do animal ao homem.

\section{A invasão animal}

A questão animal se faz presente no debate atual como uma forma de reflexão sobre as diversas relações de dominação nas sociedades contemporâneas. Suscitando discussões dessa natureza, a zoo-literatura ${ }^{1}$ constantemente expõe o destrato para com a vida animal na cultura ocidental, contestando a autoridade do homem sobre o universo zoo - autoridade forjada pelo ideal antropocêntrico. Além disso, a zoo-literatura se dedica, também, à materialização daquilo que os animais provocam à consciência hu-

1 Os textos que enfatizam a presença animal são conhecidos contemporaneamente pelo termo "zoo-literatura", como definiu Jacques Derrida (2002, p. 72). 
mana, conforme menciona Maria Esther Maciel no ensaio Literatura e animalidade (2016, p. 08):

\begin{abstract}
Os animais, sob o olhar do humano, são signos vivos daquilo que sempre escapa a nossa compreensão. Radicalmente outros, mas também nossos semelhantes, distantes e próximos de nós, eles nos fascinam ao mesmo tempo que nos assombram e desafiam nossa razão. Temidos, subjugados, amados, marginalizados, admirados, confinados, comidos, torturados, classificados, humanizados, eles não se deixam, paradoxalmente, capturar em sua alteridade radical.
\end{abstract}

Na passagem, a teórica brasileira aponta o não humano como um grande enigma a ser desvendado. Embora o homem detenha o conhecimento acerca do corpo animal, ainda não lhe é possível acessar o íntimo animal - não enquanto sua consciência estiver integralmente ligada à lógica formal -, o que embarga acesso ao próprio interior de si. A animalidade se revela, portanto, inassimilável frente à racionalidade, permitindo-se ser experimentada pelos corpos, mas não compreendida pela razão. Imaginar-se além da racionalidade seria, portanto, uma forma pela qual o homem se tornaria capaz de desvendar não somente o animal, mas também a si mesmo.

Entende-se, então, que o resgate da animalidade não corresponde, para o humano, ao despojamento da sua humanidade. Significa a recuperação da memória do próprio homem, crucial para a construção da verdadeira humanidade. A reconstituição das relações entre humano e não humano passa por um processo sob tensão, segundo Maciel, uma vez que as fronteiras homem/animal são ambíguas e paradoxais. Contudo, os limites devem ser sustentados, haja vista as inegáveis diferenças entre ambas as naturezas.

O paradoxo, apontado pela teórica brasileira, aparece frequentemente nas produções contemporâneas da zoo-literatura. O conto Carta a uma senhorita em Paris incorpora esta controvérsia 
nas relações entre homem e animal. É possível verificar uma postura repleta de dubiedade no herói errante da narrativa desenvolvida por Cortázar. Ao mesmo tempo em que ele parece opor-se à ordem lógico-formal da realidade, resigna-se a tal ordem. Constata-se, na narrativa em análise, ora uma ameaça às fronteiras homem/animal, ora um esforço para preservá-las.

Encontra-se em Giorgi outras importantes postulações que ajudam a compreender o animal não somente no texto em estudo, de Cortázar, mas também no arcabouço da Literatura Latino-Americana da atualidade. Esse teórico evidencia o deslocamento do "artefato animal" (2016, p. 12) na cultura como um movimento decisivo para definir o novo papel do animal na contemporaneidade. Portanto:

\begin{abstract}
A vida animal abandona o âmbito dessa "natureza" que a torna inteligível e que a definia em sua contraposição à vida humana, social e tecnológica; a partir dali arrasta uma série muito vasta de distinções e oposições - natural/cultural, selvagem/civilizado, biológico/tecnológico, irracional/racional, vivente/falante, orgânico/mecânico, desejo/instinto, individual/coletivo etc. - que havia ordenado e classificado corpos e formas de vida, e haviam fundado éticas e políticas. (2016, p. 9-10).
\end{abstract}

Tal movimento denuncia o que se verifica hodiernamente como uma tendência zoo-literária: o animal emerge nos espaços de poder, ameaçando a frágil civilidade do homem e criando outras gramáticas corporais, em que as inscrições biopolíticas não se aplicam facilmente. Desenvolvem-se, nessas gramáticas, potências virtuais de multiplicidade. Assim, o pensamento de Giorgi se inscreve sem dificuldade ao estudo do conto Carta a uma senhorita em Paris:

[...] o animal muda de lugar nos repertórios da cultura: a vida animal começará, de modos cada vez mais insistentes, a irromper no interior das casas, das prisões, das cidades; os espaços da política e do político verão emergir em seu interior uma vida 
animal para a qual não têm nome; sobretudo, ali onde se interrogue os corpos, seus desejos, suas doenças, suas paixões, seu afetos, ali onde o corpo se torna um protagonista e um motor de investigações estéticas e a uma só vez horizonte de apostas políticas, despontará uma animalidade que já não poderá ser separada com precisão da vida humana. (2016, p. 08).

A máquina narrativa de Cortázar, no conto em estudo, opera sob a lógica do deslocamento animal, pois os coelhos, constantes na trama, emergem no âmago da metrópole Buenos Aires, levando as estruturas da realidade antropocêntrica ao colapso. Esse fenômeno ficcional ocorre também em outros contos do autor argentino, a exemplo de Bestiário, Cefaleia e Circe - ou em produções de outros autores, como La cité des rats (1979), de Copi (1939-1987); Confabulário (1952), de Juan Jose Arreola (1918-2001); Mundo animal e outros contos (1997), de Antonio Di Benedetto (1922-1986); A ovelha negra e outras fábulas (1980), de Augusto Monterroso (19212003), etc. Como resultado, o animal se encaminha não só ao centro dos espaços de poder, mas também ao centro do inconsciente humano, recolocando a animalidade na cultura e no interior do homem.

Consequentemente, essa mudança provoca o desbotamento da distância entre o universo humano e o universo animal, permitindo com que ambos habitem em um mesmo ordenamento político, ou em um mesmo corpo, emancipado da ordem individualizante, caso exemplar de Carta a uma senhorita em Paris. O animal sempre esteve próximo do humano, mas agora a aproximação acontece de modo diferente, pois promove "[...] uma desintegração da própria noção de identidade humana [...]." (MACIEL, 2016, p. 24), o que rompe com a relação dominado/dominante.

A alteração que aponta Giorgi é importante, sobretudo, para tornar visíveis as políticas que "[...] inscrevem e classificam corpos sobre ordenamentos hierárquicos e economias da vida e da morte - isto é: os ordenamentos biopolíticos que 'produzem' corpos e Ihes atribuam lugares e sentidos num mapa social." (2016, p. 10). 
O animal estético e político em "Carta a uma senhorita em Paris", de Julio Cortázar Hiandro Bastos da Silva • Lauro Roberto do Carmo Figueira

Considerando esta lógica do deslocamento, a presença do animal desmantela as hierarquias que se instalam entre corpos no bojo social, manifestando-se contra todo regime normativo. Carta a uma senhorita em Paris concentra estes apontamentos para questionar a legitimidade das formas de vida definidas pelas tecnologias de poder, pensando a dicotomia homem $x$ animal como reflexo do paradigma "vidas por proteger e vidas por abandonar" (GIORGI, 2016, p. 12), que precisa ser subvertido.

\section{0 animal biopolítico}

A biopolítica se refere a uma tecnologia de poder que ganha notoriedade após o nascimento do Estado moderno ocidental, tendo como a principal função efetuar a gestão política da vida em larga escala, bem como o controle individual dos corpos. Assim, executando-se por meio do biopoder, articulam-se formas diversas de regulamentar a população através de políticas centradas nos processos biológicos (natalidade, mortalidade, saúde e longevidade), efetivando o domínio sobre o corpo enquanto espécie. Em relação ao corpo enquanto indivíduo, o poder disciplinar, integrado à biopolítica, considera-o como máquina, controlando suas ações, de modo que reduza suas potências, e, por outro lado, eleve suas aptidões. Isso se realiza em ambientes de cárcere, caracterizados pela natureza panóptica, como escolas, quartéis, fábricas, penitenciárias, hospitais e manicômios. Utilizando-se dessas práticas, o Estado exerce controle sobre as vidas dos corpos, condicionando-os às normativas sociais, garantindo, portanto, o direito à vida, porém, também, o poder para determinar a morte.

No curso intitulado Em defesa da sociedade, transformado em livro em 1976, Michel Foucault apresenta as primeiras reflexões acerca dessa tecnologia de poder, comprovando a sua efetivação na modernidade, e compreendendo como o seu alvo principal a vida dos corpos. Desse modo, as sociedades de controle buscam a normatização dessas vidas, adequando-as conforme as exigên- 
cias, e as tornando passíveis de proteção ou de abandono. Esse fato decorre das constantes fraturas sociais, realizadas no intuito de aplicar nos corpos a fórmula voltada ao "fazer viver e em deixar morrer" (FOUCAULT, 2005, p. 294). Logo, essa política de controle institui uma distribuição normativa que diferencia e hierarquiza os corpos, elegendo aos quais se destinam direitos ou exclusões, e a partir disso se desenvolvem os meios capazes de produzir o bem-estar biológico e social.

O "fazer viver", porém, corrobora a legitimação da violência sobre os corpos que representam ameaças à herança genética da nação. Nesses corpos, estão inscritas marcações políticas especificas (raça, classe, gênero, etc.), que traçam o limiar da vida irreconhecível, contra a qual o biopoder procura investir. Torna-se relevante pontuar que, no regime biopolítico, a vida se desatrela do referencial natural e ontológico, expressando-se fundamentalmente como um conceito jurídico-político. Em tal conceito, então, o aspecto matável reside latente, e por esse aspecto se possibilita ao biopoder dar cabo de determinadas vidas, sem grandes implicações, cumprindo a designação do "fazer viver".

Em O aberto: o homem e o animal (2002), Agamben se dedica a refletir sobre a polarização entre humanidade e animalidade, interpretada pelo filósofo italiano como a raiz de todos os conflitos. Nesse panorama, Agamben elabora o conceito de máquina antropológica: mecanismo que produz o homem em oposição ao animal, partindo de uma noção prévia de ambos. O material deixado para fora da produção do humano resultaria no "inumano" (AGAMBEN, 2017, p. 61), expresso como uma linha de indeterminação, "[...] suspenso entre uma natureza celeste e uma terrena, entre o animal e o humano [...]." (AGAMBEN, 2017, p. 51). Portanto, será de competência da máquina antropológica excluir e, ao mesmo tempo, capturar esse inumano. Existiram variadas versões da máquina antropológica ao longo da história, funcionando de maneiras diversas, porém, com a mesma finalidade: separar a vida humana da vida animal dentro do próprio humano. 
Agamben investiga este mecanismo determinante para a cultura e os costumes do Ocidente, responsável por propagar o ideal civilizatório e a primazia do homem sobre o animal. Destacam-se, assim, distinções a legitimar a vida reconhecida como humana, tendo em vista dignidade, racionalidade, linguagem e capacidade sofisticada de operações sobre a natureza. Considerando esse conjunto de qualidades e a autoconsciência, a biopolítica se utiliza da máquina antropológica da modernidade para executar com precisão seus princípios dicotômicos:

[...] está em jogo a produção do humano, por meio da oposição humano/animal, humano/inumano, a máquina funciona necessariamente por meio de uma exclusão (que é já, também e sempre, uma captura) e uma inclusão (que é também uma exclusão). Justamente porque o humano já é, com efeito, pressuposto, a máquina produz na realidade um estado de exceção, uma zona de indeterminação na qual o fora não é a exclusão de um dentro e o dentro, por sua vez, tampouco é a inclusão de um fora. (AGAMBEN, 2017, p. 61).

Essa dinâmica, no entanto, leva a crer que a articulação entre humano e não humano não é o objetivo principal da máquina antropológica em tempos biopolíticos. O que se busca, através dela, efetivamente, é transformar o corpo inumano em um campo de decisões soberanas. Nesse sentido, a presente abordagem de Carta a uma senhorita em Paris enfatiza o cruzamento da questão animal com a biopolítica para revelar o momento em que ocorre essa transformação. Assim, a divergência entre forma humana e conceito humano, em tela no conto de Cortázar, comunica sobre "[...] figuras de um animal em forma humana [...]" (AGAMBEN, 2017, p. 62), o que é basilar para a definição do inumano. Em perspectiva filosófica, sociológica e antropológica, incluem-se nessa condição judeus, negros, indígenas, estrangeiros, loucos, entre outros segmentos minoritários.

A oposição homem/animal encontra uma interessante correspondência com os vocábulos bíos e zoé, empregados por Agamben 
na obra Meios sem fim: notas sobre a política (1996). Tais palavras, provenientes da Antiguidade, eram usadas pelos gregos para se referirem ao conceito de vida. Em razão de não haver uma terminologia na língua grega para designar a dimensão do significado da palavra 'vida', empregavam as expressões bíos e zoé para constituir uma totalidade conceitual: bíos, relacionando-se à vida qualificada e reconhecível, passível de ser protegida; por seu turno, zoé, associando-se à vida desqualificada e irreconhecível, passível de ser abandonada. A vida, enfim, distribuía-se nos corpos mediante estas duas expressões, que se coordenavam entre si para um sentido global:

[...] o que se lê nessas operações do pensamento biopolítico é uma lógica de distinções ou cesuras que trabalham sobre uma premissa fundamental: corpo e subjetividade nunca se sobrepõem, do mesmo modo que população e cidadania tampouco coincidem: os modos do poder, diz a biopolítica, passam justamente por esse excesso, isso irrepresentável, inassimilável, o resto que é a linha de sombra dos corpos, o que não termina de ser individuado, identificado e humanizado, porque é em torno desse limite que se geram as decisões entre o fazer viver e o abandono, entre as vidas por proteger e as vidas por desamparar. Essa linha é a que se traça sistematicamente a partir do animal, do animalizado e da vida animal como seu ponto de tensão, de exterioridade. (GIORGI, 2016, p. 22).

A perspectiva ontológica, sobre a problemática divisão homem/animal, definiu o "especificamente humano" (GIORGI, 2016, p. 26) como construção histórica, pelo apagamento do animal. Desse modo, tal separação se tornou crucial para o empreendimento civilizatório do humanismo. Porém, ao adentrar no arbitrário jogo biopolítico, a cultura passou a perceber esta divisão homem/animal como a diferença entre “[...] vidas reconhecíveis e legíveis socialmente, e vidas opacas à ordem jurídica da comunidade." (GIORGI, 2016, p. 27). Resgatam-se, assim, os vocábulos bíos e 
zoé na contemporaneidade para indicar vidas por proteger e vidas por abandonar, respectivamente.

Seria presumível associar a vida humana ao bíos, como sendo digna de direitos, e a vida animal ao zoé, suscetível a exclusões, haja vista a tradição antropocêntrica fortemente presente no registro da realidade ocidental. No entanto, a questão não se deixa resumir de maneira simples, pois esta díade (bíos e zoé) começa a disputar a todo o momento o próprio homem. Neste sentido, basta pensar-se na figura inumana do escravo, ou do bárbaro, considerada pela máquina antropológica um animal humanizado, para se compreender que a vida humana não é índice absoluto do bíos, de algo que deve ser preservado.

Frequentemente, a ficção literária coloca em perspectiva a vida abandonável, denunciando os diferentes modos pelos quais o homem se torna a substância biopolítica invisível na esfera jurídica. Por conseguinte, a distância entre humano e não humano perde nitidez, no sentido ético, permitindo com que os atos violentos do biopoder se apliquem indistintamente em ambos. À vista disso, entende-se que, no âmbito do zoé, não se discrimina a natureza de um corpo; o homem é reduzido ao mesmo grau de vulnerabilidade do animal. Então, o artefato animal surge nas produções literárias atuais não como uma força animalizante, enlaçando os indivíduos sem condição social, mas como uma potência viva, que conjuga intensidades, afetos e desejos, para questionar os processos que fazem visíveis a vida que conta como bíos:

Por que este deslocamento nas retóricas da cultura em torno do animal é chave para o pensamento biopolítico? Porque, por um lado, evidentemente, nos permite interrogar, a partir das gramáticas formais da cultura - os modos como a cultura dá forma ao real - a evidência do humano: os modos como "humano" se faz legível e reconhecível socialmente [...]. (GIORGI, 2016, p. 27).

As distribuições homem/animal, bíos/zoé, pessoa/não pessoa, não têm outro fim senão o gerenciamento da vida em sua totalida- 
de, bem como a transformação do corpo vivente em um projeto de absoluta dominação. As práticas divisórias do biopoder criam um complexo sistema de classificações e hierarquias, que corroboram o controle normativo do ordenamento político. O conto Carta a uma senhorita em Paris conjura, por meio de artifícios imagéticos e idiomáticos, essa ordem normativa da biopolítica. Nessa direção, a rígida cadeia organizacional, que rege o espaço da narrativa, formula uma aproximação simbólica com o funcionamento da tecnologia de poder de que fala Foucault, haja vista a preocupação de que cada elemento do apartamento, habitado pelo protagonista, esteja em completa harmonia em relação aos demais. O espaço onde ocorre a história se desenha, então, como um perfeito extrato biopolítico.

O protagonista da narrativa cortaziana se revela, então, um inumano, ou seja, imerso na linha de indeterminação entre homem e animal, cujo corpo se encontra em exceção. Isso decorre por conta dos coelhos que ele regurgita em ato contínuo, sugerindo a incapacidade de isolar o não humano dentro de si. Dessa forma, esse não humano emerge pulsante no espaço normativo do apartamento, e debilita as noções indenitárias das quais o biopoder se vale para demarcar o bíos.

A linha de indeterminação entre humano e não humano, criada pela máquina antropológica, não reconcilia humanidade e animalidade. O escopo dessa estrutura ideológica é produzir uma realidade em que a violência aplicada sobre os corpos seja incondicional. Com esta compreensão, retorna-se ao paradoxo mencionado por Maciel (2016), posto que existam implicações éticas, jurídicas e políticas ao se abolir completamente as diferenças entre homem e animal, que contribuem exclusivamente para a desumanização do homem em regimes autoritários. Para se imaginar o desvelamento das fronteiras opressivas entre humano e não humano se deve, portanto, neutralizar o poder que atravessa os corpos e as subjetividades da era contemporânea. 


\section{0 animal virtual em cortázar}

O teórico argentino Gabriel Giorgi desenvolve o conceito de animal virtual no livro Formas comuns: animalidade, literatura e biopolítica (2016). Esse conceito, segundo o ensaísta, aparece no repertório do Fantástico todoroviano para responder ao fenômeno do apagamento pelo qual passa a figura do animal selvagem na cultura a partir da modernidade, decorrente das inovações tecnológicas, que promovem a gestão política da vida e da visão mercadológica da natureza. Assim, a natureza deixa de ser referência do não humano, fazendo com que a imagem do animal domesticado e enclausurado seja mais recorrente. Contudo, ao retornar à cultura como potência de ficção, o animal selvagem questiona esses processos de dominação, conforme Giorgi:

[...] a operação em torno do animal tem uma marca principal: de responder ao desaparecimento do animal selvagem como consequência da modernização - o seu ordenamento político e econômico dos corpos -, repondo-o como potência de ficção, como força incontrolável, que transborda e põe em crise as molduras de percepção do real; o animal no fantástico vem com outro tempo, que é o de uma natureza espectral, vestígio de um universo anterior à modernidade e interrupção de evidências do presente. Trata-se de um animal virtual: quer dizer, como umbral ou linha de passagem entre o real e o imaginário, entre o dado e o potencial. (2016, p. 72).

Esse animal virtual, então, implica indisciplina “[...] contra os ordenamentos dos corpos próprios das sociedades disciplinares e suas biopolíticas [...]." (GIORGI, 2016, p 72), registrando-se no arquivo autônomo do Fantástico. Os coelhos que irrompem em Carta a uma senhorita em Paris, ao adquirirem potências além do real, constituem com o protagonista uma diligência nociva à lógica de distribuição dos corpos, por isso, a simples proximidade interespécie configura indisciplina. 
Neste ponto, faz-se necessário recordar o enredo que Cortázar coloca em curso no texto: a redação de uma carta pelo protagonista (narrador autodiegético), na qual apresenta uma história aparentemente ordinária de efeito pouco dinâmico, mas com ocorrências insólitas. Uma mudança (espacial); este é o ponto de partida para o enovelamento da intriga, ou, mesmo, quando os eventos cruciais se desenrolam. O protagonista, a pedido de uma amiga, Andrée, desloca-se do campo, onde vivia confortavelmente, e parte em direção à metrópole, Buenos Aires. Ali, instala-se no apartamento da destinatária da carta, missiva esta sobre a qual se opera toda a narrativa. Andrée se encontra fora do país por razões não esclarecidas pelo narrador. Assim, configura-se a situação inicial do conto, com o protagonista no papel de proprietário temporário da casa na Suipacha (Argentina). Entretanto, ao desfecho da história, ele se verá destituído tanto do papel de proprietário temporário da casa quanto de proprietário temporário do seu próprio corpo.

No conto, idealizado conforme uma trama epistolar, destaca-se um sintoma que parece ser a principal pulsão no discurso do narrador: convencer a destinatária, Andrée, de que ele não é de todo culpado pela destruição da casa. Tal circunstância decorre corriqueiramente do hábito declarado pelo narrador que "de quando em quando, vomita um coelhinho" (CORTÁZAR, 1986, p. 23). A narrativa se precipita após esta revelação. Em decorrência do relato desse fato extraordinário, o conto desenvolve um tom de degradação até o seu epílogo.

Compreende-se que os coelhinhos regurgitados pelo personagem emergem dentro do contexto da concepção de animal virtual postulado por Giorgi (2016): um artefato de potência, cuja força incontrolável promove crise do modelo comum do real, além de transpô-lo, gerando níveis de percepção além do mundo ordinário. Neste modelo de percepção de vida histórica, que dialoga com o absurdo, a incontrolável emergência dos coelhinhos de dentro do protagonista vai de encontro à noção de gestão biopolítica, representada na organização do apartamento. Essa gestão se ba- 
seia em ações coordenadas que visam classificar e hierarquizar os corpos de uma população. Isso se manifesta alegoricamente no conto pelo modo como tudo na casa parece se organizar seguindo uma rígida ordem:

[...] me desagrada entrar em uma ordem fechada, construída até nas mais finas malhas do ar, essas que em sua casa preservam a música da lavanda, o adejar de um cisne, o jogo de violino e viola no quarteto de Rará. Para mim é duro entrar em um ambiente onde alguém que vive confortavelmente dispôs tudo como uma reiteração de sua alma, aqui os livros (de um lado em espanhol, do outro em francês e inglês), ali os almofadões verdes, neste exato lugar da mesinha, o cinzeiro de cristal que se parece com uma bolha de sabão, e sempre um perfume, um som, um crescer de plantas, uma fotografia do amigo morto, um ritual de bandejas com chá e pinças de açúcar... Ah, querida Andrée, que difícil opor-se, embora aceitando-a com inteira submissão do próprio ser, à minuciosa ordem que uma mulher instaura em sua agradável residência (CORTÁZAR, 1986, p. 21).

O trecho em questão evoca uma certeza: a insatisfação do protagonista em ter que habitar aquele local. Pode-se inferir, dessa insatisfação, que ele compreende a si mesmo como pertencente a uma lógica outra, para além do comensurável. Contudo, nota-se a recusa para reconhecer esta verdade, frequentemente reprimida, conforme ratifica o próprio narrador: “[...] de quando em quando me acontece vomitar um coelhinho. Não é razão para não viver em qualquer casa, não é razão para que a gente tenha de se envergonhar e estar isolado e andar se calando." (CORTÁZAR, 1986, p. 23).

O excerto em destaque, no entanto, carrega indícios de um desejo ambíguo do protagonista integrar-se à ordem da lógica vigente. Ele se posiciona, em diferentes situações, como alguém ávido de se desvincular da animalidade que o constrange e faz de si um desvio da norma. Há todo um cuidado da sua parte para não se deixar encantar pelos coelhinhos - ato que, consequentemente, significaria deixar-se encantar pela condição de inumano cada vez mais iminente. Esse encantamento, que o protagonista tenta 
evitar, é responsável por criar uma espécie de elo reconciliador entre homem e animal; um ajuntamento que não define nem um dos dois como agente dominante, revelando uma tensão híbrida na condição humana. Essa dubiedade sustenta uma crise na máquina antropológica, sobre a qual trata Agamben:

A máquina antropológica não articula mais natureza e homem para produzir o humano através da suspensão e captura do inumano. A máquina, por assim dizer, está presa, em "estado de detenção" e, na suspensão recíproca dos dois termos, algo para o qual talvez não tenhamos nomes e que não é mais animal nem homem instala-se entre natureza e humanidade, mantém-se na relação do animal, na noite salva. (2017, p. 130).

Em Carta a uma senhorita em Paris a decisão do protagonista de aplicar estratégias coordenadas em uma ocorrência do campo da irrealidade potencializa o absurdo no comportamento do homem consciente da sua racionalidade. Esta incongruência entre o sujeito analisador e o objeto analisado é uma crítica amena de Cortázar ao modo como o homem distorce o incompreensível para torná-lo compreensível. As estruturas da compreensão lógica dos fatos são sutilmente assediadas no conto ao tom de um ritmo erroneamente pacífico de escrita. Assim, os procedimentos empreendidos pelo protagonista, para preservar a ordem do caos, que no início da trama gozavam de certo êxito, revelam-se ineficazes após a mudança para a casa de Andrée:

Veja você, eu tinha resolvido inteiramente o problema dos coeIhinhos. Plantava trevo na varanda de minha outra casa, vomitava um coelhinho, punha-o no trevo e, ao fim de um mês, quando suspeitava que de um momento para outro... então dava o coeIho já crescido à sra. de Molina, que pensava ser um hobby meu e se calava. Já em outro vaso vinha crescendo um trevo novo e apropriado, eu esperava sem preocupação a manhã em que a cosquinha de uma penugem subindo fechava-me a garganta, e o novo coelhinho repetia desde aquela hora a vida e os costumes do anterior. (CORTÁZAR, 1986, p. 24). 
A personagem Andrée, por sua vez, é apresentada como sujeito fundamentalmente cartesiano, que, em relação aos móveis e objetos da sua casa: "dispôs tudo como uma reiteração de sua alma" (CORTÁZAR, 1986, p. 21). Isso inclui a criada Sara, cuja presença se faz tão opaca e vazia de subjetividade que aparenta ser somente mais um elemento milimetricamente acomodado no apartamento. Nesse ponto, verifica-se uma crítica à concepção de pertença capitalista, que torna coisas e seres como patrimônio do indivíduo. A construção de Andrée como sujeito cartesiano marca os territórios do ordinário em face do extraordinário. Desse modo, a racionalidade submete à sua vontade o elemento irracional. Todavia, a potência animal, que irradia das entranhas do protagonista, verga sua vontade de contê-la, embora contrariado. Em que pese à psique turbulenta do protagonista, é urgente para ele convencer a amiga de que o hábito de regurgitar coelhinhos não é demasiado incomum, mas, por outro lado, é incontrolável. Esta faculdade, por fim, gera a ruína da casa.

Os coelhinhos, após a mudança de cenário do protagonista, passam a comportar-se como o fluxo contínuo de uma verdade desconhecida, que não sugere término. Essas figuras, que na prática cotidiana são de fácil domesticação, ganham desmedida força no texto e fazem de si próprias instâncias indomáveis. Neste arranjo, o protagonista não se dedica a mais nada, a não ser trabaIhar e cuidar do contingente de láparos, mantendo-os trancados no armário durante o dia, e soltando-os durante a noite. $\mathrm{O}$ ato de ocultar os animais corresponde a um princípio da máquina antropológica, o de isolar o animal no homem:

O desafio que vem dessa irrupção do animal na ordem social, essa ameaça inatribuível, identifica-se com a ficção: isso é o que faz o fantástico; joga com os limites entre ficção e realidade marcando um salto ou uma quebra nas dimensões ou umbrais do real, e faz do animal o operador desse salto: o animal retorna à cultura como espectro, como ficção, como irrealidade, para marcar a crise no inteligível (GIORGI, 2016, p. 73). 
Os coelhinhos são inseridos por Cortázar no espaço da ficção fantástica, em que as potências vagam livres. Carta a uma senhorita em Paris é um nítido exemplo de como são trabalhadas pelo autor essas potências no intuito de colocar abaixo as bases da razão. Essa operação é posta em jogo mediante a quebra do ritmo no surgimento dos animais, que começam a emergir aceleradamente. Isso configura uma quebra na rotina criada pelo protagonista, tornando-se insustentável para ele. Ocorre, porém, antes dos fatos que definem o desfecho do conto, um mero lampejo de esperança: os coelhinhos vomitados somam dez, ao todo, desde a chegada à casa da amiga. Por um momento, tudo parece estabilizar-se, causando algum alívio ao protagonista. Todavia, sua desgraça não tarda. Ele vomita o décimo primeiro coelhinho, levando-o ao estado de absoluta desesperança. Esta última investida da animalidade, do acontecimento insólito, a transbordar das entranhas do inumano, da consciência lógico-racional, encaminha a narrativa a um fim trágico:

Quis em vão tirar os pelos que estragam o tapete, arranjar a moldura da tela roída, fechá-los de novo no armário. O dia chega, talvez Sara se levante agora. É quase estranho que Sara não me importe. E quase estranho que não me importe vê-los correr em busca de brinquedos. Não tive tanta culpa, você verá quando chegar que muitos dos destroços estão bem reparados com a cola que comprei em uma casa inglesa, eu fiz o que pude para evitar-Ihe um desgosto... Quanto a mim, do dez ao 11 há como um vazio insuperável. Você vê: dez estava bem, com um armário, trevo e esperança, quantas coisas se podem construir. Mas não com 11, porque dizer 11 é certamente dizer 12. Andrée, 12 que será 13. Então está o amanhecer e uma fria solidão na qual cabem a alegria, as recordações, você e talvez tantos outros. Está esta sacada sobre Suipacha cheia de aurora, os primeiros sons da cidade. Não acho que seja difícil juntar 11 coelhinhos salpicados sobre os paralelepípedos, talvez nem os notem, atarefados com o outro corpo que convém levar logo, antes que passem os primeiros colegiais. (CORTÁZAR, 1986, p. 32). 
O animal estético e político em "Carta a uma senhorita em Paris", de Julio Cortázar Hiandro Bastos da Silva • Lauro Roberto do Carmo Figueira

No final do conto, ecoa a ideia de que "[...] a vida não cabe nos corpos da realidade [...]" (GIORGI, 2016, p. 78). Sendo assim, o protagonista opta por findar a sua existência inconciliável, que foi deixada nos limites do humano, distante do bíos; daquilo que conta como vida reconhecível, segundo o biopoder. Não conseguindo, portanto, suportar as pulsões do ordenamento normativo, do qual não fazia parte, em decorrência de sua condição ambivalente, atravessada por instâncias que a indetermina, o protagonista se afasta deste universo de causalidade simétrica. O animal virtual, segundo a concepção aqui adotada, que migra da natureza para dentro das casas, e posteriormente para dentro dos corpos, simboliza a animalidade à procura do humano, como uma parte perdida dele: "[...] tão da gente que a gente mesmo... e depois tão a gente, tão isolado e distante em seu raso mundo branco tamanho mapa." (CORTÁZAR, 1986, p. 25).

\section{Considerações finais}

O estudo realizado ambicionou decifrar a vertiginosa presença do animal no conto cortaziano Carta a uma senhorita em Paris. A animália que transita no universo da obra Bestiário reinsere no cotidiano a animalidade, vínculo comum entre todos os seres do universo criatural, para se instaurar novas relações no ordenamento jurídico. Todavia, esse processo ocorre de maneira inusitada, tipicamente relacionada à modalidade ficcional do Fantástico. Atentando-se ao conto Carta a uma senhorita em Paris, averiguaram-se os momentos em que o animal reivindica seu espaço neste 'terreno experimental', entendido como vida pelo senso comum.

À vista desta iminência animal, expôs-se o funcionamento da máquina antropológica - engenhoso mecanismo biopolítico, que inaugura o advento tecnológico humano em consequência da supressão do não humano. Porém, tal advento da máquina antropológica não passa de uma suposição do que é o humano. Assim, a máquina parte de pressupostos para criar a dicotomia entre ho- 
mem e animal, atualizando-se frequentemente no intuito de mantê-la ao longo da história. O corpo do homem é o espaço onde ocorre o processo de separação, ou seja, isola-se o não humano dentro do próprio humano. A 'falha' desta separação produz o inumano, matéria fundamental em uma realidade onde a exceção se torna regra. A análise de Carta a uma senhorita em Paris traduz literariamente o funcionamento hostil desse mecanismo.

Por sua vez, a aproximação entre homem e animal, visualizada na relação do protagonista com os coelhos, lê-se como o retorno do animal ao homem. Nessa perspectiva, torna-se bastante sugestivo os coelhos surgirem de dentro do protagonista, compreendendo-se como aquilo que passa a habitar no homem. Assim, percebe-se, na história de Cortázar, o animal invadindo a vida, o cotidiano e a cidade.

Carta a uma senhorita em Paris afirma ainda a presença do animal no inconsciente do contemporâneo, que se comprova a partir da emergência dos coelhos na realidade imediata. No entanto, este movimento sofre repressões, em decorrência das retaliações da máquina antropológica, acionada por conta da ameaça que a relação homem/animal pode causar aos seus binarismos. Por sua vez, as estruturas de poder, implícitas no texto, determinam a morte do personagem, imposta a ele por intermédio do suicídio. Não obstante ao desfecho trágico, o conto deixa, além de reflexões filosóficas, imaginações poéticas acerca do íntimo animal - a maior delas diz respeito ao outro dialético, presente nas profundezas do eu, sob a sombra do animal.

\section{Referências}

AGAMBEN, Giorgio. Meios sem fim: notas sobre a política. Belo Horizonte: Autêntica, 2015.

O aberto: o homem e o animal. Rio de Janeiro: Civilização Brasileira, 2017.

ARREOLA, Juan Jose. Confabulário. Curitiba: Arte \& Letra, 2015. 
O animal estético e político em "Carta a uma senhorita em Paris", de Julio Cortázar Hiandro Bastos da Silva • Lauro Roberto do Carmo Figueira

BENEDETTO, Antonio Di. Mundo animal e outros contos. Porto Alegre: Editora Globo, 2008.

COPI. La cité des rats. Paris: Belfond, 1979.

CORTÁZAR, Julio. Bestiário. Rio de Janeiro: Nova Fronteira, 1984.

DERRIDA, Jacques. O animal que logo sou. São Paulo: Unesp, 2002.

FOUCAULT, Michel. História da sexualidade: A vontade de saber. Rio de Janeiro: Gallimard, 1988. v. 1

Em defesa da sociedade. São Paulo: Martins Fontes, 2005.

GIORGI, Gabriel. Formas comuns: animalidade, literatura e biopolítica. Rio de Janeiro: Rocco, 2016.

MACIEL, Maria Esther. Literatura e animalidade. Rio de Janeiro:

Civilização Brasileira, 2016.

MONTERROSO, Augusto. A ovelha negra e outras fábulas. São Paulo:

Cosac \& Naify, 2014.

ROAS, David. A ameaça do fantástico. São Paulo: Unesp, 2013.

TODOROV, Tzvetan. Introdução à literatura fantástica. São Paulo:

Perspectiva, 2007. 